\title{
Vitreous Hemorrhage Caused by Ruptured Retinal Macroaneurysm
}

\author{
Kazunobu Asao Atsuko Nakada Yoshimi Kawasaki \\ Department of Ophthalmology, Takarazuka Daiichi Hospital, Hyogo, Japan
}

\section{Key Words}

Vitreous hemorrhage $\cdot$ Ruptured retinal macroaneurysm · Optic disc $\cdot$ Prognosis

\begin{abstract}
Purpose: To report the clinical findings of 7 patients with a vitreous hemorrhage (VH) caused by a ruptured retinal macroaneurysm. Methods: Interventional case series. The medical records of 7 patients with a VH caused by a ruptured macroaneurysm and treated by either medication or vitrectomy were reviewed. The main outcome measures were the visual acuity, appearance of the fundus and optical coherence tomographic findings. Results: Two patients, aged 49 and 58 years, had retinal macroaneurysms at the optic disc. The retinal macroaneurysm in the other 5 eyes (mean age 79.0 years) was not at the optic disc. The VH was completely resolved in all 7 patients. The visual acuity improved in all eyes and remained stable for at least 6 months after the treatments $(p=0.0478)$. Conclusions: The improvement of the visual acuity in all eyes indicates that the prognosis of eyes with a $\mathrm{VH}$ caused by a ruptured retinal macroaneurysm is good.

(c) 2014 S. Karger AG, Basel
\end{abstract}

\section{Introduction}

A vitreous hemorrhage ( $\mathrm{VH})$ is a serious complication of different diseases such as proliferative diabetes retinopathy, branch retinal vein occlusion, retinal tear, exudative agerelated macular degeneration, trauma, and ruptured retinal arterial macroaneurysms [1-3]. $\mathrm{VH}$ is also associated with retinal vascular disorders such as diabetes mellitus, systemic hypertension and vascular malformations [1-3].

Most patients with retinal arterial macroaneurysms are older and usually have a history of systemic hypertension. They also have ophthalmoscopic evidence of retinal arteriosclerosis. The incidence of VH caused by a ruptured retinal arterial macroaneurysm is not high [2-

Kazunobu Asao, MD

Department of Ophthalmology

Takarazuka Daiichi Hospital

19-5, Kogetsu-cho, Takarazuka-shi, Hyogo 665-0832 (Japan)

E-Mail hirosaki1001@gmail.com 
4]. However, when the hemorrhage is at the fovea, there is a marked reduction in the visual acuity [5].

A VH may be absorbed spontaneously in some cases, but other cases require pars plana vitrectomy (PPV) to remove the hemorrhage because the hemorrhage can lead to retinal tears and retinal detachments, causing a further reduction in vision [2].

Past studies have shown that PPV has a relatively good visual outcome in eyes with a macroaneurysm [6]. However, the secondary effects of retinal arterial macroaneurysms have not been completely determined.

We describe our findings in 7 cases of VH caused by a ruptured retinal macroaneurysm.

\section{Materials and Methods}

Seven eyes of 7 patients, 4 men and 3 women, were studied, beginning in April 2012 until November 2013. The patients had a VH caused by a ruptured macroaneurysm and were treated with hemostatics (kalliginogenase) and a circulatory agent (carbazochrome sodium sulfonate hydrate) or PPV. The patients were followed for at least 6 months. All patients signed an informed consent form for the treatment. The study adhered to the tenets of the Declaration of Helsinki. Records of all patients seen in the Takarazuka Daiichi Hospital are stored in an electronic database.

Patients had a complete ophthalmic examination that included measurements of the best-corrected visual acuity (BCVA) using Landolt C charts, slit-lamp examinations, and indirect ophthalmoscopy. If necessary, a fundus examination was performed that included fundus photography, B-scan ultrasonography, optical coherence tomography (OCT; RS-3000, Nidek, Gamagori, Japan), and fluorescein angiography (FA; TRC-50LX, Topcon, Tokyo, Japan) during the follow-up period.

After appropriate counselling, each patient was offered treatment with medication or vitrectomy. For those who selected vitrectomy, a standard 3-port PPV was performed using a 25-gauge system by the same experienced surgeons. Phacoemulsification and intraocular lens implantation were combined in all phakic eyes.

We determined whether each of the patients had risk factors for a VH such as sex, hypertension, and age. At the first examination after the $\mathrm{VH}$, we confirmed the presence of a subretinal hemorrhage (SRH) and the location of the macroaneurysm (if the fundus was visible). If it was not visible, we performed the same examination after the VH had disappeared. The changes in the BCVA were recorded during the follow-up period. The decimal BCVA was converted into the logarithm of the minimal angle of resolution (logMAR) for statistical analyses.

Statistical analysis was carried out using the JMP software version 11.0 (SAS Inc, Cary, N.C., USA), with $\mathrm{p}<0.05$ considered to be significant.

\section{Results}

Seven patients ( 4 men, 3 women) with a mean age of $71.7 \pm 14.2$ years and a range of 49 to 91 years, who were examined between April 2012 and November 2013, were studied. None of the patients had a history of diabetes mellitus, but 3 had hypertension. Five patients were over 70 years of age and 2 were under 60 .

Two patients (49 and 58 years) had a macroaneurysm at the optic disc, and 5 patients (mean 79.0 years, range 71-91 years) had a macroaneurysm, but not at the optic disc; 2 had 
et al.: Vitreous Hemorrhage Caused by Ruptured Retinal Macroaneurysm

it in the nasal-inferior, 1 in the temporal-inferior, and 2 in the temporal superior quadrants. The mean follow-up was 9.9 months, with a range of 6 to 19 months.

The mean BCVA was a 0.90 logarithm of the logMAR units at the time the hemorrhage was detected. Five patients received medication, e.g. hemostatics (kalliginogenase) or an antihemorrhagic or hemostatic agent (carbazochrome sodium sulfonate hydrate). Two patients underwent vitrectomy. The average BCVA improved to $-0.04 \operatorname{logMAR}$ units at 3 months $(\mathrm{p}=0.0417)$ and $-0.05 \log$ MAR units at 6 months $(\mathrm{p}=0.0478)$ after treatment. The improvement in the BCVA was sustained for the duration of the follow-up period (table 1). No patient suffered any side effect related to the medication or the vitrectomy.

Fundus examinations showed that the macula edema and the subretinal hemorrhage in the macular area were not present in any of the eyes. FA did not show any other source of the VH, except the macroaneurysm. The OCT images showed that the macroaneurysm was at the optic disc in 2 patients and was not accompanied by a subretinal hemorrhage. The other macroaneurysms were not at the optic disc and were accompanied by a subretinal hemorrhage. No eyes had a posterior vitreous detachment. We also determined that no patients had risk factors such as age, sex, hypertension, location of the macroaneurysm, and SRH for a VH (table 1).

\section{Case Reports}

Case 1

A 58-year-old woman had a sudden appearance of floaters in her right eye. She was neither hypertensive nor diabetic. At the initial visit, her BCVA was -0.18 logMAR units in the right eye and $-0.20 \log$ MAR units in the left eye. The slit-lamp findings were unremarkable in both eyes. Fundus examination revealed a ruptured retinal arterial macroaneurysm at the optic disc and a small VH (fig. 1). The OCT image did not show a subretinal hemorrhage and edema around the macroaneurysm. Only hemostatics (kalliginogenase) and circulatory agents (carbazochrome sodium sulfonate hydrate) were prescribed because no retinal detachment was observed by B-scan ultrasonography. Three months later, her BCVA remained at $-0.18 \operatorname{logMAR}$ units, and the size of the ruptured macroaneurysm decreased. Six months later, she had no recurrences and her BCVA remained at -0.18 logMAR units.

\section{Case 2}

An 82-year-old woman had a sudden decrease of vision in her left eye. She had hypertension and was taking antihypertensive medication. At the initial examination, her BCVA was $2.0 \operatorname{logMAR}$ units in the left eye. The results of the slit-lamp examination were unremarkable in both eyes. Her fundus could not be observed because of the massive VH; however, B-scan ultrasonography did not show a retinal detachment. One month after medicinal treatment, the VH was not resorbed and vitrectomy was performed. After the hemorrhage was removed, a ruptured macroaneurysm with subretinal hemorrhage was detected within the vascular arcade (fig. 2). After the surgery, the macroaneurysm became atrophic, and the subretinal hemorrhage gradually decreased. The OCT images showed a subretinal hemorrhage around the ruptured macroaneurysm. Three months later, the BCVA improved to $-0.18 \log$ MAR units and the macroaneurysm was atrophic. The size of the subretinal hemorrhage near the macroaneurysm was reduced. Six months later, she has had no recurrences, and the BCVA remained at $-0.18 \log M A R$ units. 
et al.: Vitreous Hemorrhage Caused by Ruptured Retinal Macroaneurysm

\section{Discussion}

Our results showed that there was an improvement of the BCVA in all patients after medication or vitrectomy in eyes with a ruptured retinal arterial macroaneurysm. This indicates that the prognosis after a $\mathrm{VH}$ associated with a retinal arterial macroaneurysm is good.

Earlier studies showed that the incidence of retinal arterial macroaneurysms was higher in women, and the patients were older with a high incidence of systemic hypertension [3]. Approximately $2 \%$ of all $\mathrm{VH}$ is caused by a rupture of a macroaneurysm [2]. Occasionally, the macroaneurysm may not be detected because of the overlying hemorrhage [7]. Therefore, careful follow-up examinations are needed in eyes with VH.

Structurally, the hemorrhages derived from a ruptured macroaneurysm are generally present in specific retinal layers, but large aneurysmal dehiscences can lead to hemorrhages at all levels of the retina [8]. In those eyes with an arterial macroaneurysm away from the optic disc, the macroaneurysm led to a SRH, but the SRH eventually decreased spontaneously. A SRH from a retinal arterial macroaneurysm can cause destruction of the foveal photoreceptor layer resulting in a poor vision and outcome [9]. In our cases, there was no subretinal hemorrhage, which might account for the good BCVA.

Earlier studies showed that the closer the macroaneurysm was to the disc, the higher the pressure will be on its wall, and the greater the chance that its size will increase $[3,4]$. The stress increases exponentially along with the increase of the arterial diameter $[3,4]$. Therefore, hemorrhagic macroaneurysms tended to be located significantly closer to the optic disc [3]. This fact could explain the hemorrhages, but not the SRH. We suggest that the pressure might be dispersed and the hemorrhage might spread not only into the retina, but also into the vitreous body at the optic disc. When VH occurs in young patients, vitreopapillary traction appears to play an important role in the genesis of the peripapillary subretinal hemorrhages [10]. However, there were some patients who had a SRH without a posterior vitreous detachment [11]. Two of our patients had a ruptured macroaneurysm at the optic disc, but did not have peripapillary subretinal hemorrhages and a posterior vitreous detachment. These findings suggest that a posterior vitreous detachment can be the cause of the SRH from macroaneurysms. However, there may be other factors than the structural factor.

If there is no history of hypertension and diabetes mellitus, it is necessary to determine the cause in other congenital retinal vascular anomalies such as collagen disease, Coats' disease, Leber's miliary aneurysms, and von Hippel-Lindau diseases [3, 10-14]. In addition, we must rule out granulomatous diseases such as sarcoidosis, toxoplasmosis, and tuberculosis, which can also produce a mass on the optic disc [14].

The limitations of this study were its retrospective nature, the small number of eyes and the lack of a uniform treatment of the hemorrhage. In addition, the follow-up period was short. Another shortcoming was the absence of a control group that did not receive treatment after $\mathrm{VH}$ developed. In addition, different medications and vitrectomy were used to treat the eyes, and therefore the reasons for the good results are uncertain. A larger case series is necessary to clarify the prognosis of $\mathrm{VH}$ associated with ruptured RAMs.

In summary, we report our findings in 7 cases of a vitreal hemorrhage caused by a ruptured retinal arterial macroaneurysm. Treatment with medications or vitrectomy led to good visual outcomes in all patients. 


\begin{tabular}{l|l}
\hline \multicolumn{2}{l}{ Case Rep Ophthalmol 2014;5:44-49 } \\
\hline DOI: 10.1159/000358796 & $\begin{array}{l}\text { C 2014 S. Karger AG, Basel } \\
\text { www.karger.com/cop }\end{array}$ \\
\hline
\end{tabular}

et al.: Vitreous Hemorrhage Caused by Ruptured Retinal Macroaneurysm

\section{References}

1 Saxena S, Jalali S, Verma L, Pathengay A: Management of vitreous haemorrhage. Indian J Ophthalmol 2003;51:189-196.

2 Goff MJ, McDonald HR, Johnson RN, Ai E, Jumper JM, Fu AD: Causes and treatment of vitreous hemorrhage. Compr Ophthalmol Update 2006;7:97-111.

-3 Lavin MJ, Marsh RJ, Peart S, Rehman A: Retinal arterial macroaneurysms: a retrospective study of 40 patients. Br J Ophthalmol 1987;71:817-825.

4 Tezel T, Günalp I, Tezel G: Morphometrical analysis of retinal arterial macroaneurysms. Doc Ophthalmol 1994;88:113-125.

5 Hirano K, Mitamura Y, Ogata K, Yamamoto S: Three cases of retinal arterial macroaneurysm on the optic disc (in Japanese). Nihon Ganka Gakkai Zasshi 2010;114:801-804.

-6 Moosavi RA, Fong KC, Chopdar A: Retinal artery macroaneurysms: clinical and fluorescein angiographic features in 34 patients. Eye (Lond) 2006;20:1011-1020.

7 Spalter HF: Retinal macroaneurysms: a new masquerade syndrome. Trans Am Ophthalmol Soc 1982;80:113-130.

-8 Nakamura H, Hayakawa K, Sawaguchi S, Gaja T, Nagamine N, Medoruma K: Visual outcome after vitreous, sub-internal limiting membrane, and/or submacular hemorrhage removal associated with ruptured retinal arterial macroaneurysms. Graefes Arch Clin Exp Ophthalmol 2008;246:661-669.

-9 Tsujikawa A, Sakamoto A, Ota M, Oh H, Miyamoto K, Kita M, Yoshimura N: Retinal structural changes associated with retinal arterial macroaneurysm examined with optical coherence tomography. Retina 2009;29:782-792.

10 Katz B, Hoyt WF: Intrapapillary and peripapillary hemorrhage in young patients with incomplete posterior vitreous detachment. Signs of vitreopapillary traction. Ophthalmology 1995;102:349-354.

-11 Sibony P, Fourman S, Honkanen R, El Baba F: Asymptomatic peripapillary subretinal hemorrhage: a study of 10 cases. J Neuroophthalmol 2008;28:114-119.

12 Rabb MF, Gagliano DA, Teske MP: Retinal arterial macroaneurysms. Surv Ophthalmol 1988;33:73-96.

13 Ichibe M, Oya Y, Yoshizawa T, Abe H: Macroaneurysm on the optic disk associated with congenital retinal arterial malformation. Retina 2004;24:985-986.

14 Mitamura Y, Miyano N, Suzuki Y, Ohtsuka K: Branch retinal artery occlusion associated with rupture of retinal arteriolar macroaneurysm on the optic disc. Jpn J Ophthalmol 2005;49:428-429.

Table 1. Demographic and clinical data of patients with ruptured macroaneurysms

\begin{tabular}{|c|c|c|c|c|c|c|c|c|c|c|}
\hline \multirow[t]{2}{*}{ Patients } & \multirow{2}{*}{$\begin{array}{l}\text { Age, } \\
\text { years }\end{array}$} & \multirow[t]{2}{*}{ Sex } & \multirow[t]{2}{*}{ Eye } & \multirow[t]{2}{*}{ Location } & \multicolumn{3}{|c|}{ logMAR BCVA } & \multirow{2}{*}{$\begin{array}{l}\text { Hyper- } \\
\text { tension }\end{array}$} & \multirow{2}{*}{$\begin{array}{l}\text { Opera- } \\
\text { tion }\end{array}$} & \multirow{2}{*}{ SRH } \\
\hline & & & & & initial visit & $\begin{array}{l}3 \text { months } \\
\text { after }\end{array}$ & $\begin{array}{l}6 \text { months } \\
\text { after }\end{array}$ & & & \\
\hline 1 & 71 & M & $\mathrm{R}$ & nasal inferior & 0.4 & -0.18 & -0.18 & + & - & + \\
\hline 2 & 76 & $\mathrm{~F}$ & $\mathrm{R}$ & nasal inferior & -0.08 & 0 & 0 & + & - & + \\
\hline 3 & 75 & M & $\mathrm{L}$ & temporal inferior & 0.15 & -0.18 & 0 & - & - & + \\
\hline 4 & 91 & $\mathrm{M}$ & $\mathrm{R}$ & temporal superior & 2 & 0.52 & 0.3 & - & - & + \\
\hline 5 & 58 & $\mathrm{~F}$ & $\mathrm{R}$ & optic disc & -0.18 & -0.18 & -0.18 & - & - & - \\
\hline 6 & 82 & $\mathrm{~F}$ & $\mathrm{~L}$ & temporal superior & 2 & -0.18 & -0.18 & + & + & + \\
\hline 7 & 49 & M & $\mathrm{R}$ & optic disc & 2 & -0.08 & -0.08 & - & + & - \\
\hline
\end{tabular}


Case Reports in

Ophthalmology
Case Rep Ophthalmol 2014;5:44-49

DOI: $10.1159 / 000358796$

et al.: Vitreous Hemorrhage Caused by Ruptured Retinal Macroaneurysm

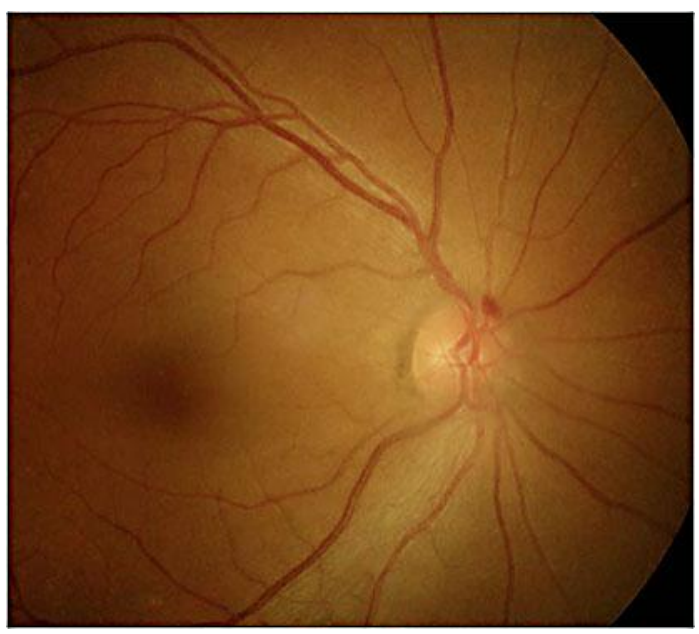

Fig. 1. Fundus photograph showing retinal arterial macroaneurysm at the optic disc (case 1).

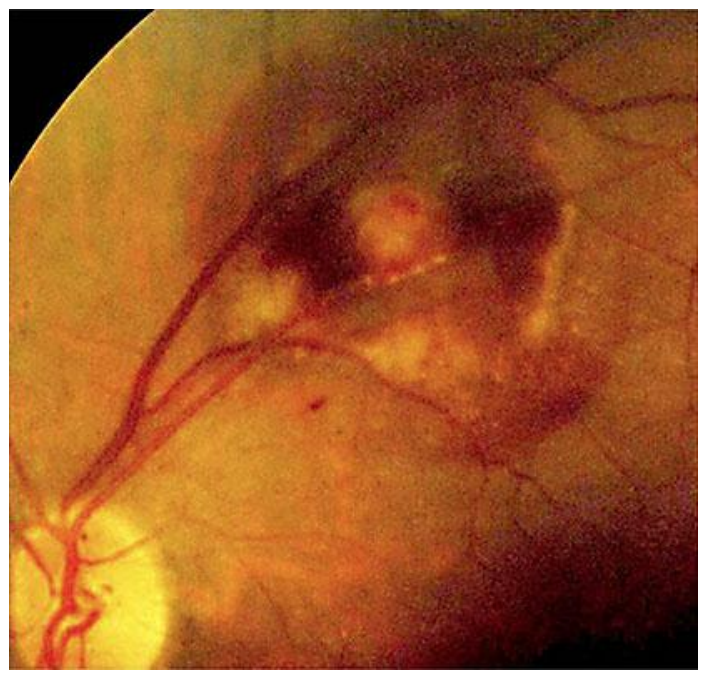

Fig. 2. Fundus photograph showing of retinal arterial macroaneurysm with a subretinal hemorrhage within the arcade (case 2). 